\title{
Development and Evaluating Content Validity of Clinical Skill Analysis Index Tools
}

\author{
Thandar Soe Sumaiyah Jamaludin ${ }^{1}$, Mohd. Said Nurumal ${ }^{2 *}$ (D), Norfadzilah Ahmad ${ }^{3}$, Siti Aesah Naznin Muhammad $^{4}$ \\ Chong Mei Chan ${ }^{5}$ \\ ${ }^{1}$ Department of Medical Surgical Nursing, Kulliyyah of Nursing, International Islamic University Malaysia, Kuantan, Pahang, \\ Malaysia; ${ }^{2}$ Department of Critical Care Nursing, Kulliyyah of Nursing, International Islamic University Malaysia, Kuantan, \\ Pahang, Malaysia; ${ }^{3}$ Department of Professional Nursing Studies, Kulliyyah of Nursing, International Islamic University Malaysia, \\ Kuantan, Pahang, Malaysia; ${ }^{4}$ Department of Pathology and Laboratory Medicine, Kulliyyah of Medicine, International Islamic \\ University Malaysia, Kuantan, Pahang, Malaysia; ${ }^{5}$ Department of Nursing, University of Malaya, Kuala Lumpur, Malaysia
}

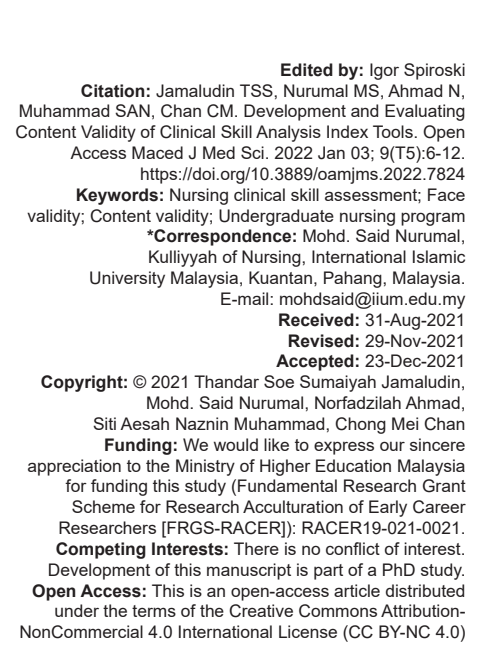

\section{Abstract}

BACKGROUND: The current structured nursing clinical skill assessment checklist is steps driven and the soft skills component is fragmented and limited.

AIM: This study aimed to evaluate the face and content validity of a tool that had been developed to assess the current structured clinical skill assessment for the Malaysian undergraduate nursing program.

METHODS: The face and content validity of the instrument were examined based on the opinions of experts. The item content validity index and scale content validity index (S-CVI) were calculated by using the mean approach and inter-rater agreement. The content validity of the instrument was assessed by S-CVI/UA and S-CVI/Ave. The scale was revised based on comments from a panel of eight experts in the first review stage and thereafter, evaluated by another group of three experts in the second review stage.

RESULTS: There were nine soft skills elements identified for the clinical skill analysis index (CSAl) tools in this study. Those were communication skill, social skill and responsibility, critical thinking skill, problem-solving skill, teamwork, leadership skill, professional and ethical decision-making skill, numeracy skill, and interpersonal skill. The findings a the face validity stage yielded ten domains with eight nursing core procedures areas being retained, based on $95 \%$ or more agreement from expert responses. The result of S-CVI/UA and S-CVI/Ave of the CSAI tools yielded scores of 0.91 and 1 respectively.

CONCLUSION: Findings indicated that this instrument had an excellent face and content validity to assess the current structured clinical skill assessment for the Malaysian undergraduate nursing program.

\section{Introduction}

There are many clinical assessment methods that have been used to assess nursing student's competency level in clinical skills of the current undergraduate nursing program. Among them, objective structured clinical examination (OSCE) has been widely used as a formative and summative assessment to assess the clinical subjects in health-related medical educations including nursing education [1]. Moreover, the OSCE is widely considered to provide a reliable and valid assessment of clinical skills and is superior to traditional methods based on the physical examination of real patients, the evaluation of oral presentations of cases, and written work [1].

Although the OSCE has been considered as a standard tool to assess student's clinical competencies skill, the checklist in OSCE has confronted educationalists with problems of validity and reliability over an extended period [2], [3]. Another study found that the OSCE, while very successful in assessing individual components of clinical competence, does not conventionally enable assessment of the student's care for the patient as a whole [4]. Furthermore, the purpose of clinical skill assessment is to prepare and induct nursing students to work as safe, ethical, and accountable nurses in a clinical setting [5]. Thus, the assessment ought to consider the multidimensional nature of competence and the attributes required for the nursing profession [6].

On the other hand, acquiring soft skills competencies becomes increasingly important and relevant for the nursing profession. Studies showed that employers still find the graduates lacking relevant soft skills competencies required in their job positions which lead to their unemployment in a highly competitive job market [7], [8]. Moreover, every graduate nurse should pose two types of skills which are hard skills and soft skills. The hard skills are the hands-on procedural skills that nursing students learn in their training days which allow them to perform their nursing care effectively. Soft skills 
are the skills nursing student need to communicate and accommodate effectively and get along in their workplace. Both skills are extremely critical to nursing profession and patient care in the current complex health care setting.

Moreover, soft skills are so important in nursing profession that they are sometimes seen as more valuable than hard skills and technical knowledge. In the current modern days, every employer is very aware of the soft skills value when they want to hire the staff. There is a gap in nursing students gaining soft skills from their theory classes and the application of it. A previous study found that soft skills should be part of the training that student nurses receive during their professional training [9]. Another study found that paying attention not only to the material world of human but also his or her soul and spirituality dimension when dealing with ill patients [10]. Furthermore, it was suggested that the subject area to investigate the effect of the integration on soft skills in the undergraduate nursing program is extremely recommended for future study. A recent systematic review study found that there is a need to consider and adopt soft skill elements in clinical skill assessment to improve the quality of nursing graduates and ultimately to create a positive impact on patient outcomes [11].

In the current structured nursing clinical skill assessment, most of the time the assessors are focusing on the assessment of student's dexterity and frequently lack out on assessment of their soft skills. Furthermore, the current OSCE checklist is steps driven and soft skills component is fragmented, limited and students still passed the exam although they are not applying the soft skills in their clinical skill assessment. Thus, graduate students are becoming skills orientated instead of holistic competent graduate nurses. Although with sophisticated health care technology and a growing trend toward diverse healthcare environment, the graduate nurses must understand the benefit of soft skills to their careers and personal lives.

Thus, we believe that the development of clinical skill analysis index (CSAI) tools to access the currently structured nursing clinical skills assessment would benefit for the undergraduate nursing program. Furthermore, it would help nursing academics to teach soft skills and have the opportunity to add significant value to their students' learning and assessment. Therefore, this study aimed to evaluate the face and content validity of a tool that had been developed to assess the currently structured clinical skill assessment for the Malaysian undergraduate nursing program.

\section{Methods}

\section{Tool development}

The development, content validation, and content validity index calculation of the CSAI tools in this study were applied the approaches described by previous studies [12], [13], [14]. These CSAI tools were developed in four major phases by the researcher and the team. In the phase I focused on establishing the conceptual and operational definitions of the construct to ensure content validity through the previous literature review. During the second phase, conducting the systematic literature review of the published literatures, the current undergraduate nursing program's curriculum review, and the nursing competency skill logbook review were carried. Then, in the third phase, the first stage of content validation procedure was carried out with six steps guided by a previous study [14]. Finally, in the fourth phase, the second stage of content validation and finalization of the CSAI tools were sought. The following Figure 1 shows the flow and process of the CSAI tools development and the content validation method used in this study.

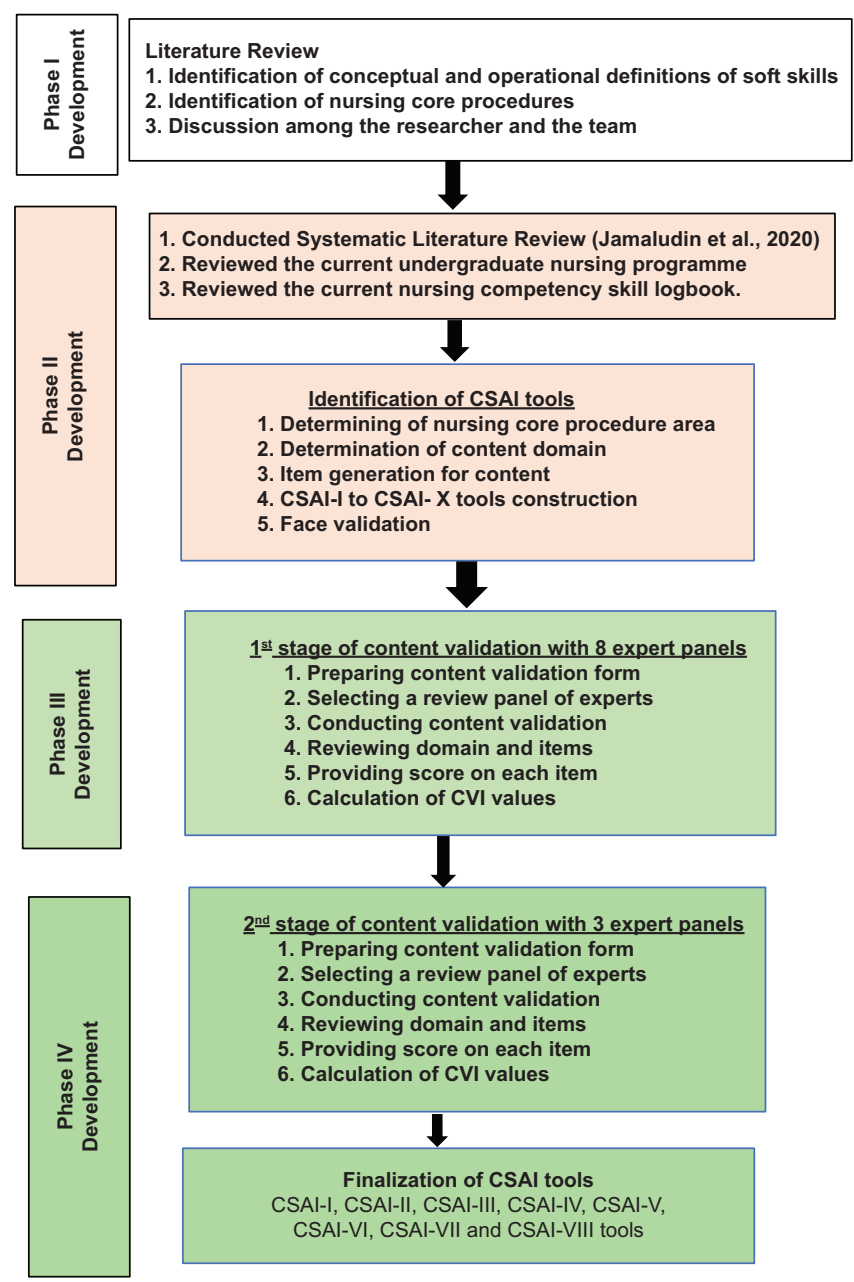

Figure 1: The CSAI tools development phases. CSAI: Clinical skill analysis index

In the phase I of CSAI tools development, the researcher has done a critical review of the previous literature to look for the theoretical and conceptual definition of soft skills and the nursing core procedures for the undergraduate nursing program. Then, the researcher proceeds with the formation of an operational definition for soft skills. Then, the researcher brought all those information to the supervisory team for discussion of this phase I of CSAI tools development. 
After getting confirmation from the team, the researcher proceeds with phase II which is conducting the systematic review on existing literature. At the same time, the researcher also did the review of the current undergraduate nursing programs's clinical skill procedures together with the current nursing competency skill logbook. After reviewing all those things, the researcher and the team have identified the CSAI tools which contained nursing core procedures area determination, content domain, item generation for the content, and tool construction for phase II of CSAI tools development. Then, the researcher and the team were given the name of the CSAI tools as CSAI-I, CSAI-II, CSAI-III, CSAI-IV, CSAI-V, CSAI-VI, CSAI-VII, CSAI-VIII, CSAI-IX, CSAI-X. Those CSAI-I to CSAI-X tools have ten nursing core procedures areas and eleven domains with 42 items in this phase II development. Domain 1 to domain 8 used the dichotomous option (Yes or No), and domains 9 and 10 used opened statement.

Those ten nursing core procedure areas included in the CSAI-I to CSAI-X tools were named as; (I) medication procedure, (II) transfusion procedure, (III) dressing procedure, (IV) aseptic procedure, (V) health education procedure, (VI) assisted procedure, (VII) basic nursing procedure, (VII) specimen collection procedure, (IX) procedure for therapeutic education for chronic diseases, and $(X)$ other nursing procedures.

The 11 domains of the CSAI-I to CSAI-X tools are (1) type of procedure, (2) soft skill elements, (3) equipment, (4) instruction for student, (5) the clinical scenario, (6) model usage, (7) duration of the procedure, (8) How many marks is allocated for soft skills? (9) Opportunity of soft skills that can be measured in the particular procedure, (10) Any Assistance provided for the procedure? And (11) Overall remarks for improvement. The sample of CSAI-I tool can be seen in Table 1.

For all the CSAI-I to CSAI-X tools, there were nine soft skill elements identified in this study. Those were communication skill, social skill and responsibility, critical thinking skill, problem-solving skill, teamwork, leadership skill, professional and ethical decisionmaking skill, numeracy skill, and interpersonal skill.

\section{Face validation of the CSAI tools}

Then, the researcher has proceeded for the determination of face validity for the CSAI-I to CSAI-X tools by showing to experts and get their viewpoints on this tool before proceeding to the next phase. The experts involved in this study were medical academics, nursing academics, and nurse clinicians from local and international universities and hospitals. Furthermore, the chosen experts in this study have more than 7 years of clinical supervision experience with medical and nursing students. The face validity means if the designed instrument is apparently related
Table 1: CSAI-I tool (at phase II development)

\begin{tabular}{|c|c|c|c|c|}
\hline \multicolumn{5}{|c|}{ Area 1: Medication procedure } \\
\hline S. No. & Domain & Items & & \\
\hline \multirow[t]{11}{*}{1.} & Type of procedure & & Yes & No \\
\hline & & 1. Administering oral medication & & \\
\hline & & 2. Administering intravenous medication & & \\
\hline & & 3. Administering intradermal medication & & \\
\hline & & 4. Administering subcutaneous medication & & \\
\hline & & 5. Administering the eye or ear medication & & \\
\hline & & 6. Administering dangerous drugs & & \\
\hline & & 7. Administering suppository medication & & \\
\hline & & 8. Administering topical medication & & \\
\hline & & 9. Administering intramuscular medication & & \\
\hline & & 10. Administering inhalation medication & & \\
\hline \multirow[t]{10}{*}{2.} & Component of soft & & Yes & No \\
\hline & skill elements in the & 1. Communication skill & & \\
\hline & checklist & 2. Social skill and responsibility & & \\
\hline & & 3. Critical thinking skill & & \\
\hline & & 4. Problem solving skill & & \\
\hline & & 5. Teamwork & & \\
\hline & & 6. Leadership skill & & \\
\hline & & 7. Professional and ethical decision-making skill & & \\
\hline & & 8. Numeracy skill & & \\
\hline & & 9. Interpersonal skill & & \\
\hline \multirow[t]{6}{*}{3.} & Equipment & & Yes & No \\
\hline & & 1. Equipment has been laid out for student & & \\
\hline & & $\begin{array}{l}\text { 2. Equipment has been laid out with } \\
\text { unnecessary requirement }\end{array}$ & & \\
\hline & & 3. Student need to prepare themselves & & \\
\hline & & 4. Others & & \\
\hline & & Specify ------------ & & \\
\hline \multirow[t]{4}{*}{4.} & $\begin{array}{l}\text { Instruction for the } \\
\text { student }\end{array}$ & $\begin{array}{l}\text { 1. How many minutes allocated for student } \\
\text { to read? }\end{array}$ & & \\
\hline & & Specify ---_---o-- & & \\
\hline & & & Yes & No \\
\hline & & 2. Is the instruction given clearly? & & \\
\hline \multirow[t]{7}{*}{5.} & Clinical scenario & & Yes & No \\
\hline & & 1. Simple & & \\
\hline & & 2. Medium & & \\
\hline & & 3. Complex & & \\
\hline & & 4. Complete & & \\
\hline & & & Yes & No \\
\hline & & $\begin{array}{l}\text { 5. Is the clinical scenario match with the } \\
\text { assessment objective? }\end{array}$ & & \\
\hline \multirow[t]{5}{*}{6.} & Model & 1. Mannequin & & \\
\hline & & 2. High fidelity & & \\
\hline & & 3. Actor & & \\
\hline & & & Yes & No \\
\hline & & $\begin{array}{l}\text { 4. Do the model used is suitable for the } \\
\text { procedure being assessed? }\end{array}$ & & \\
\hline \multirow[t]{4}{*}{7.} & Duration & 1. $5 \mathrm{~min}$ & & \\
\hline & & 2. $>5 \mathrm{~min}$ & & \\
\hline & & 3. Others & & \\
\hline & & Specify --- & & \\
\hline 8. & $\begin{array}{l}\text { How many marks is } \\
\text { allocated for soft skills? }\end{array}$ & Specify --.--_-_---- & & \\
\hline 9. & $\begin{array}{l}\text { Opportunity of soft } \\
\text { skills that can be } \\
\text { measured in the } \\
\text { particular procedure }\end{array}$ & Specify ---. & & \\
\hline \multirow[t]{2}{*}{10.} & Any Assistance is & 1. Yes & & \\
\hline & $\begin{array}{l}\text { provided for the } \\
\text { procedure? }\end{array}$ & 2. No & & \\
\hline 11. & $\begin{array}{l}\text { Overall remarks for } \\
\text { improvement }\end{array}$ & Specify ---.-- & & \\
\hline
\end{tabular}

to the construct underlying study [15]. Do the experts agree with items and wording of them in a tool to realize research objectives? Furthermore, face validity is related to the appearance and apparent attractiveness of the tool.

\section{Content validation of the CSAI tools}

The content validation of the CSAI tools was carried in the next two phases. In the phase III, the researcher and the team have carried out for the first stage of content validation procedure with eight expert panels. In this stage, the six steps of content validation procedure were applied based on the previous study [14]. Those six steps were: preparing content 
validation form, selecting a review panel of experts, conducting content validation, reviewing domain and items, providing a score on each item, calculation of content validity index (CVI) values. The preparation of content validation form is to ensure the review panel of experts will have clear expectation and understanding about the task [14]. A sample of instruction and rating scale in the content validation form of CSAI tools to the experts can be viewed at Figure 2.

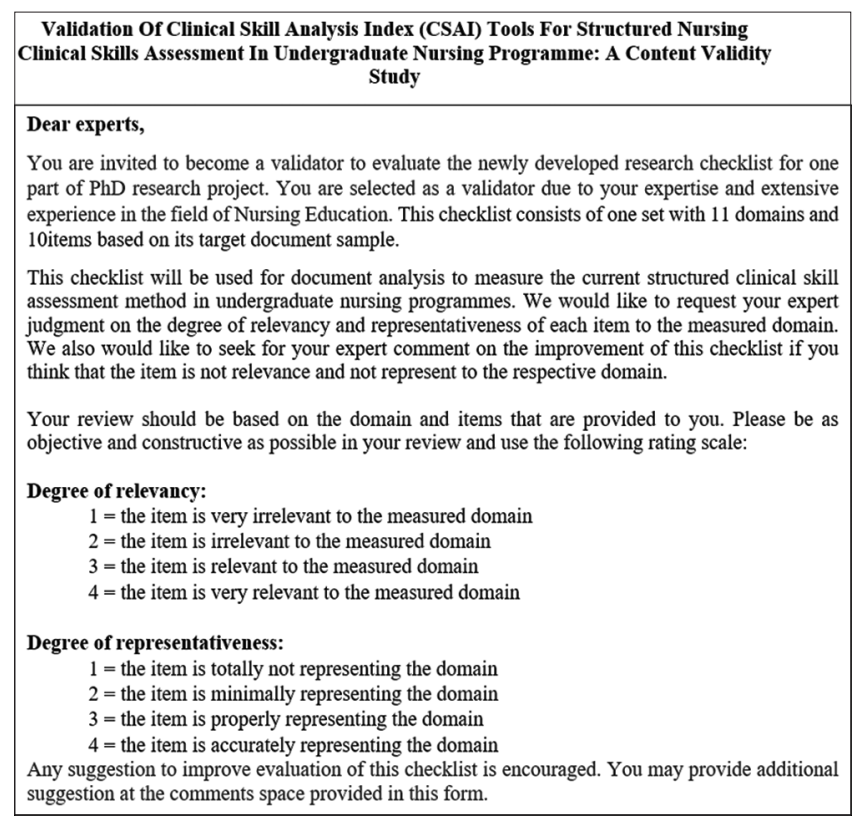

Figure 2. A sample of instruction and rating scale in the content validation form of CSAI tools to the experts

This content validity study was carried out after obtaining the ethical approval from the faculty and the respective ethic committees. This study completed within 12 months periods for all four phases. The validators were given the time frame from 2 to 4 weeks to complete the validation process. The item CVI (I-CVI) and scale CVI (S-CVI) were calculated by adopting the mean approach and inter-rater agreement. To calculate an I-CVI, experts are asked to rate the relevancy of each item on measured domain and item representation on the domain with a 4-point scale. Figure 3 shows a sample of layout for content validation form of CSAI tools with domain, and tested items represent (measure) the domain. The S-CVI/UA (scale-level content validity index based on the universal agreement method) and S-CVI/Ave (scale-level content validity index based on the average method) of the CSAI tools were also assessed in this study.

The CSAI tools were revised based on comments from a panel of eight experts in the first review stage, and thereafter, evaluated by another group of three experts with the same procedure in the second review stage at phase IV. Finally, there were eight CSAI tools were yielded in this study. Those final version of CSAI tools were namely as CSAI-I, CSAI-II, CSAI-III, CSAI-IV, CSAI-V, CSAI-VI, CSAI-VII, and CSAI-VIII.

There were eight nursing core procedure areas with ten domains were included in the checklist of the CSAI-I to CSAI-VIII tools. The eight nursing core procedure areas were named as; (I) medication procedure, (II) transfusion procedure, (III) aseptic procedure, (IV) health education procedure, (V) assisted procedure, (VI) basic nursing procedure, (VII) specimen collection procedure, and (VIII) other nursing procedures. The ten domains of the CSAI-I to CSAI-VIII tools are; (1) type of procedure, (2) soft skill elements, (3) equipment, (4) instruction for student, (5) the clinical scenario, (6) model usage, (7) duration of the procedure, (8) assistance, (9) how many marks are allocated for soft skills, (10) the opportunity of soft skills that can be measured in the particular procedure. The sample of the final version of the CSAI-I tool can be seen in Table 2 .

\section{CSAI-I tool}

\begin{tabular}{|c|c|c|c|c|c|}
\hline Aared & Domain & Tested Items & & & \\
\hline \multirow{10}{*}{1.} & \multirow{10}{*}{ Type of procedure } & & Relevancy & Representative & COMMENTS \\
\hline & & 1) Administering oral medication & \multirow{9}{*}{$\begin{array}{rrrr}1 & 2 & 3 & 4 \\
0 & \bigcirc & \bigcirc & \bigcirc\end{array}$} & \multirow{9}{*}{$\begin{array}{llll}1 & 2 & 3 & 4 \\
\bigcirc & \bigcirc & \bigcirc & \bigcirc\end{array}$} & \\
\hline & & 2) Administering intravenous (IV) medication & & & \\
\hline & & 3) Administering intradermal (ID) medication & & & \\
\hline & & 4) Administering subcutaneous (SC) medication & & & \\
\hline & & 5) Administering the eye or ear medication & & & \\
\hline & & 6) Administering dangerous drugs (DDA) & & & \\
\hline & & 7) Administering suppository medication & & & \\
\hline & & 8) Administering topical medication & & & \\
\hline & & 9) Administering intramuscular (IM) medication & & & \\
\hline & \multirow{10}{*}{$\begin{array}{l}\text { Component of soft } \\
\text { skill elements in the } \\
\text { checklist }\end{array}$} & & Relevancy & Representative & COMMENTS \\
\hline & & 1) Communication skill & \multirow{9}{*}{$\begin{array}{llll}1 & 2 & 3 & 4 \\
\bigcirc & \bigcirc & \bigcirc & \bigcirc\end{array}$} & \multirow{9}{*}{$\begin{array}{llll}1 & 2 & 3 & 4 \\
\bigcirc & \bigcirc & \bigcirc & \bigcirc\end{array}$} & \\
\hline & & 2) Social skill and responsibility & & & \\
\hline & & 3) Critical thinking skill & & & \\
\hline & & 4) Problem solving skill & & & \\
\hline & & 5) Teamwork & & & \\
\hline & & 6) Leadership skill & & & \\
\hline & & 7) Professional and ethical decision-making skill & & & \\
\hline & & 8) Numeracy skill & & & \\
\hline & & 9) Interpersonal skill & & & \\
\hline \multirow{5}{*}{$\sqrt{7}$} & \multirow{4}{*}{ Equipment } & & Relevancy & Representative & COMMENTS \\
\hline & & 2) Equipment has been laid out with unnecessary requirement & \multirow{3}{*}{$\begin{array}{lrrr}1 & 2 & 3 & 4 \\
\bigcirc & \bigcirc & \bigcirc & \bigcirc\end{array}$} & \multirow{3}{*}{$\begin{array}{llll}1 & 2 & 3 & 4 \\
\bigcirc & \bigcirc & \bigcirc & \bigcirc\end{array}$} & \\
\hline & & 3) Student need to prepare themselves & & & \\
\hline & & 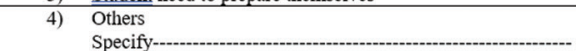 & & & \\
\hline & & 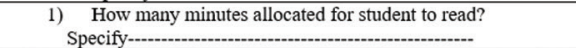 & & & \\
\hline
\end{tabular}

Figure 3. A sample of layout for content validation form of CSAI tools with domain, and tested items represent (measure) the domain 


\section{Results}

The findings at the face validity stage yielded 10 domains with 8 nursing core procedures being retained, based on $95 \%$ or more agreement from expert responses. The content validity of the instrument was assessed by S-CVI/UA and S-CVI/ Ave, yielding scores of 0.91 and 1 , respectively, as shown in Tables 3 and 4 . The acceptable CVI values should have at least 0.75 if using three to five experts in the content validity study [13].

\section{Discussion}

The existing tools developed by previous researchers for the nursing clinical skills assessment

Table 2: CSAI-I tool (at phase IV development)

\begin{tabular}{|c|c|c|c|c|c|c|}
\hline Area 1 & cation procedure & & & & & \\
\hline S. No. & Domain & Items & & & & \\
\hline 1. & Type of procedure & & & & Yes & No \\
\hline & & 1. Administering oral medication & & & & \\
\hline & & 2. Administering intravenous medication & & & & \\
\hline & & 4. Administering subcutaneous medication & & & & \\
\hline & & 5. Administering the eye or ear medication & & & & \\
\hline & & 6. Administering dangerous drugs & & & & \\
\hline & & 7. Administering suppository medication & & & & \\
\hline & & 8. Administering topical medication & & & & \\
\hline & & 10. Administering inhalation medication & & & & \\
\hline 2. & Component of soft skill elements in the checklist & & & & Yes & No \\
\hline & & 1. Communication skill & & & & \\
\hline & & 2. Social skill and responsibility & & & & \\
\hline & & 3. Critical thinking skill & & & & \\
\hline & & 4. Problem solving skill & & & & \\
\hline & & 5. Teamwork & & & & \\
\hline & & 6. Leadership skill & & & & \\
\hline & & 7. Professional and ethical decision-making ski & & & & \\
\hline & & 8. Numeracy skill & & & & \\
\hline & & 1. Equipment has been laid out for student & & & & \\
\hline & & 2. Equipment has been laid out with unnecesse & iry requirement & & & \\
\hline & & 3. Student need to prepare themselves & & & & \\
\hline & & 4. Others & & & & \\
\hline & & 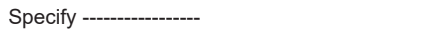 & & & & \\
\hline 4. & Instruction for the student & 1. How many minutes allocated for student to $r$ & ead? & & & \\
\hline & & Specify --------------- & & & & \\
\hline & & & & & Yes & No \\
\hline & & 2. Is the instruction given clearly? & & & & \\
\hline 5. & Clinical scenario & & & & Yes & No \\
\hline & & 1. Simple & & & & \\
\hline & & 2. Medium & & & & \\
\hline & & 3. Complex & & & & \\
\hline & & 4. Complete & & & & \\
\hline & & & & & Yes & No \\
\hline & & 5. Is the clinical scenario match with the asses & ment objective? & & & \\
\hline 6. & Model & 1. Mannequin & & & & \\
\hline & & 2. High fidelity & & & & \\
\hline & & 3. Actor & & & & \\
\hline & & & & & Yes & No \\
\hline & & 4. Do the model used is suitable for the proced & ure being assessed? & & & \\
\hline & & 3. Others & & & & \\
\hline & & Specify -..-_- & & & & \\
\hline & & 4. Is the time allocation is enough to complete & he procedure? & & & \\
\hline 8. & Assistance & & & & Yes & No \\
\hline & & Any Assistance is provided for the procedure? & & & & \\
\hline 9. & How many marks is allocated for soft skills? & Specify --.--_- & & & & \\
\hline 10. & Opportunity of soft skills that can be measured in the & Communication skill & Social skill and responsibilities & Critical thinking skill & & \\
\hline & particular procedure & Problem-solving skill & Teamwork skill & Leadership skill & & \\
\hline & & Professional and ethical decision-making skill & Numeracy skill & Interpersonal skill & & \\
\hline
\end{tabular}

CSAl: Clinical skill analysis index

Table 3: $1^{\text {st }}$ stage of content validation with 8 expert panels

\begin{tabular}{|c|c|c|c|c|c|c|c|c|c|c|}
\hline & Expert 1 & Expert 2 & Expert 3 & Expert 4 & Expert 5 & Expert 6 & Expert 7 & Expert 8 & Experts in agreement & Item CVI \\
\hline Item 1 & 4 & 4 & 4 & 4 & 4 & 4 & 4 & 4 & 4 & 1 \\
\hline Item 2 & 4 & 3 & 4 & 3 & 4 & 4 & 4 & 4 & 3.8 & 0.9 \\
\hline Item 3 & 4 & 3 & 4 & 4 & 4 & 4 & 4 & 3 & 4 & 0.9 \\
\hline Item 4 & 4 & 3 & 3 & 4 & 3 & 4 & 4 & 3 & 3.9 & 0.9 \\
\hline Item 6 & 3 & 2 & 3 & 3 & 4 & 4 & 4 & 4 & 3.9 & 0.8 \\
\hline Item 7 & 4 & 3 & 3 & 4 & 3 & 4 & 3 & 4 & 3.9 & 0.9 \\
\hline Item 8 & 3 & 4 & 4 & 4 & 4 & 4 & 4 & 4 & 4 & 1.0 \\
\hline Item 9 & 4 & 4 & 3 & 4 & 4 & 4 & 3 & 3 & 3.8 & 0.9 \\
\hline Item 10 & 4 & 3 & 4 & 4 & 4 & 4 & 3 & 4 & 4 & 0.9 \\
\hline Item 11 & 4 & 3 & 4 & 4 & 3 & 4 & 2 & 4 & 4 & 0.9 \\
\hline Proportion relevant & 0.95 & 0.82 & 0.98 & 0.95 & 0.9 & 1 & 0.89 & 0.9 & (Average I-CVI) & 0.91 \\
\hline
\end{tabular}

CVI: Content validity index, I-CVI: Item content validity index 
Table 4: $2^{\text {nd }}$ stage of content validation with three expert panels

\begin{tabular}{llllll}
\hline & Expert 1 & Expert 2 & $\begin{array}{l}\text { Expert 3 } \\
\text { Experts in } \\
\text { agreement }\end{array}$ & $\begin{array}{l}\text { Item CVI } \\
\text { (S-CVI/UA and S-CVI/ } \\
\text { Ave) }\end{array}$ \\
\hline Item 1 & 4 & 4 & 4 & 4 & 1 \\
Item 2 & 4 & 4 & 4 & 4 & 1 \\
Item 3 & 4 & 4 & 4 & 4 & 1 \\
Item 4 & 4 & 4 & 4 & 4 & 1 \\
Item 5 & 4 & 4 & 4 & 4 & 1 \\
Item 6 & 4 & 4 & 4 & 4 & 1 \\
Item 7 & 4 & 4 & 4 & 4 & 1 \\
Item 8 & 4 & 4 & 4 & 4 & 1 \\
Item 9 & 4 & 4 & 4 & 4 & 1 \\
Item 10 & 4 & 4 & 4 & 4 & 1 \\
Proportion relevant & 1 & 1 & 1 & (Average & 1 \\
& & & & I-CVI) \\
CVI: Content validity index, I-CVI: Item content validity index, S-CVI: Scale content validity index
\end{tabular}

were mainly focused on the students and graduate nurses's clinical performance [6], [16], [17]. They have used those developed tools in the OSCE to assess students' clinical competencies. Furthermore, those developed tools (clinical assessments) are too often focused on psychomotor skills and fail to consider the multidimensional nature of competence and the large range of attributes required for (Soft skills) professional practice. Moreover, no study has been clearly described on the importance of soft skills elements to be integrated and it should be assessed in a nursing clinical skills assessment.

In this study, the researcher and the team were identified 9 soft skills to be a component of soft skill elements in the checklist of each CSAI tools as described in the result and the sample in Table 2. The operational definitions of the 9 soft skills are based on the nursing core procedure areas in the CSAI-I to CSAIVIII tools. For instance, the operational definition of leadership skill from CSAI-I (medication procedure) and CSAI-IV (health education) has different. Moreover, the panel of experts from the $1^{\text {st }}$ stage and $2^{\text {nd }}$ stage have agreed on the 9 soft skills which should be in all the CSAI tools. Thus, this is the special part about the CSAI tools compared to the existing tools that available to assess the clinical skill competency of nursing students and graduate nurses.

Furthermore, this study evaluated the face and content validity of a newly developed CSAI-I to CASIVIII tools to access the currently structured nursing clinical skills assessment in the undergraduate nursing program. Results showed that the face validity of the CASI tools was established; the domains and items of each tool reviewed by the panel of experts indicated that it was appropriate for this study purpose. In addition, the content validity of the instrument was also evaluated.

Based on the feedback received from the panel of experts, the nursing core procedure areas, domain, and items of this CSAI tools was revised and modified in selected parts to ensure that the degree of relevancy and representativeness of each item of questionnaire was adequate. Items with lower than acceptable levels of content validity were discarded. The original pool that consisted of 10 nursing core procedures eleven domains of competencies was reduced to 8 nursing core procedures and 10 domains after the second stage reviewed. Subsequently, this CSAI tools were judged as having excellent content validity. The researcher and the team were hoping that using this CSAI tools to assess the clinical skills of nursing students would have better outcome for nursing profession in the future.

\section{Conclusion}

It is crucial to have a well-structured clinical skill assessment tool to assess the nursing students' competency level in order to produce holistic graduate nurses who equip with clinical skills and soft skills for the current healthcare delivery system. Thus, the finding of the face and content validity of the CSAI tools indicated that all the experts are highly agreed on the content and valid to assess the current structured clinical skill assessment for the Malaysian undergraduate nursing program. Moreover, this study findings will be useful for nursing academics to teach and assess the soft skills on their students' clinical skill performance. After all, soft skills are so important in nursing that they are sometimes seen as more valuable than hard skills and technical knowledge.

\section{Ethic Approval}

Ethical approval from the ethic committee of International Islamic University Malaysia (IREC 2019129) was obtained for this study.

\section{References}

1. Harden RM, Lilley P, Patricio M. The Definitive Guide to the OSCE: The Objective Structured Clinical Examination as a performance assessment. Amsterdam, Netherlands: Elsevier Health Sciences; 2016.

2. Setyonugroho W, Kennedy KM, Kropmans TJ. Reliability and validity of OSCE checklists used to assess the communication skills of undergraduate medical students: A systematic review. Patient Educ Couns. 2015;98(12):1482-91.

3. Tor E, MacNish J, Wrtight A, Steketee C. Improving the Validity and Reliability of OSCE Scores through a Comprehensive Measurement Instrument; 2011.

4. Traynor M, Galanouli D. Have OSCEs come of age in nursing education? Br J Nurs. 2015;24(7):388-91. https://doi. org/10.12968/bjon.2015.24.7.388 PMid:25849236

5. Bourbonnais FF, Langford S, Giannantonio L. Development of a clinical evaluation tool for baccalaureate nursing students. Nurse Educ Pract. 2008;8(1):62-71. https://doi.org/10.1016/j. nepr.2007.06.005. 


\section{PMid:17728186}

6. Levett-Jones T, Gersbach J, Arthur C, Roche J. Implementing a clinical competency assessment model that promotes critical reflection and ensures nursing graduates' readiness for professional practice. Nurse Educ Pract. 2011;11(1):64-9. https://doi.org/10.1016/j.nepr.2010.07.004

PMid:20727825

7. Hairi F, Toee MA, Razzaly W. Employers' perception on soft skills of graduates: A study of Intel elite soft skill training. In: Paper presented at the International Conference on Teaching and Learning in Higher Education; 2011.

8. Nasution SS. Stakeholder Perception about Soft Skill Graduated Faculty of Nursing Universitas Sumatera Utara; 2020

9. Laari L, Dube BM. Nursing students' perceptions of soft skills training in Ghana. Curationis. 2017;40(1):e1-5. https://doi. org/10.4102/curationis.v40i1.1677

\section{PMid:29041781}

10. Nurumal MS, Jamaludin TS, Ahmad N, Muhammad SA, Chan $\mathrm{CM}$. Integration of Islamic values in undergraduate nursing program: An expository analysis. Int J Care Sch. 2017;16:1.

11. Jamaludin TS, Nurumal MS, Ahmad N, Muhammad SA, Chan CM. Soft skill elements in structured clinical nursing assessment for undergraduate nursing students: A systematic review. Enferm Clin. 2021;31:S58-S62. https://doi.org/10.1016/j. enfcli.2020.10.019

12. Lynn MR. Determination and quantification of content validity Nurs Res. 1986;35(6):382-5.

PMid:3640358

13. Polit DF, Beck CT, Owen SV. Is the CVI an acceptable indicator of content validity? Appraisal and recommendations. Res Nurs Health. 2007;30(4):459-67. https://doi.org/10.1002/nur.20199 PMid:17654487

14. Yusoff MS. ABC of content validation and content validity index calculation. Educ in Med J. 2019;11(2):49-54. https://doi. org/10.21315/eimj2019.11.2.6

15. Zamanzadeh V, Ghahramanian A, Rassouli M, Abbaszadeh A Alavi-Majd H, Nikanfar AR. Design and implementation content validity study: Development of an instrument for measuring patient-centered communication. J Caring Sci. 2015;4(2):16578. https://doi.org/10.15171/jcs.2015.017

PMid:26161370

16. Fidment $\mathrm{S}$. The objective structured clinical exam (OSCE) Aqualitative study exploring the healthcare student's experience. Stud Engagem Exp J. 2012;1(1):1-18.

17. Traynor M, Galanouli D, Rice B, Lynn F. Evaluating the objective structured long examination record for nurse education. Br J Nurs. 2016;25(12):681-7. https://doi.org/10.12968/bjon.2016.25.12.681 PMid:27345072 